\title{
Lung Perfusion Scanning in Hepatic Cirrhosis
}

\author{
N. N. STANLEY， P. ACKRILL， J. WOOD
}

British Medical fournal, 1972, 4, 639-643

\section{Summary}

Abnormal lung perfusion scans using radioactive particles were found in five out of six cases of hepatic cirrhosis with arterial hypoxaemia. None had clinical evidence of cardiopulmonary disease or signs of pulmonary embolism on arteriography. The scan defects are probably caused by a disorder of the pulmonary microvasculature, which may show regional variation in severity.

\section{Introduction}

Arterial hypoxaemia is a well known complication of hepatic cirrhosis. From a physiological viewpoint it is caused by a pulmonary gas exchange defect due to either true shunting (Georg et al., 1960) or ventilation-perfusion ( $\dot{V} / \mathbf{Q})$ inequality (Cotes et al., 1968); reduction of pulmonary transfer factor is also common (Stanley and Woodgate, 1972). Postmortem examination of the lung when using vascular injection techniques usually discloses widespread dilation of small vessels (Berthelot et al., 1966) and occasionally may show multiple small arteriovenous anastomoses (Rydell and Hoffbauer, 1956). In addition, there have been isolated reports of pulmonary hypertension (Murray et al., 1958; Segel et al., 1968). The cause of this is uncertain but may be thromboembalic in some cases (Senior et al., 1968). This paper is concerned with an abnormality of the pulmonary circulation found by lung perfusion scanning with radioactive particles in cases of hepatic cirrhosis with hypoxaemia.

\section{Patients and Methods}

Lung scans were obtained in 12 patients with hepatic cirrhosis, which had been firmly established by their clinical, biochemical, and liver biopsy findings. They included six with arterial hypoxaemia, which had previously been discovered and evaluated by the procedures outlined below. No patient had

Department of Medicine, Royal Free Hospital, London N.W.3

N. N. STANLEY, M.B., M.R.C.P., Research Fellow (Present address: Cardiovascular-Pulmonary Division, Hospital of the University of Pennsylvania, Philadelphia, Pennsylvania 19104, U.S.A.)

P. ACKRILL, M.B., M.R.C.P., RegistrattPresent address: St. Bartholomew's Hospital, London E.C.1)

J. WOOD, M.sC., M.nNST.P., Senior Physicist

clinical evidence of cardiopulmonary disease or ascites at the time of study. Their clinical data are summarized in Table I.

While lying supine, each patient was given an intravenous injection of macroaggregated albumin (MAA) particles labelled with either $0.2-0.3 \mathrm{mCi}$ of ${ }^{181} \mathrm{I}$ or $0.5-2.0 \mathrm{mCi}$ of ${ }^{\prime \prime m} \mathrm{Tc}$, which resulted in maximum radiation doses to the lungs of about 2 or 0.3 rads respectively. The particle size was always checked beforehand and unless otherwise stated it averaged 20-50 microns in diameter. Anterior and posterior colour scans and photoscans were made with a Picker Magnascanner V, except in one case where a posterior colour scan only was obtained with a Selo DS 7 scanner. These scans were assessed by comparison with other normal scans and the relative perfusion of different regions was judged by eye.

Selective pulmonary arteriograms were obtained in all patients with abnormal lung scan appearances. Physiological evaluation in every case included the measurement of forced vital capacity (FVC), forced expiratory volume in one second $\left(F E V_{1}\right)$, single breath carbon monoxide transfer factor, and arterial $\mathrm{O}_{2}$ tension. Right heart catheterization, arterial cannulation, and collection of expired gas were performed in six of these patients. Pressures were recorded in the right side of the heart and in the pulmonary artery. Arterial and mixed venous blood were analyzed for $\mathrm{Po}_{2}, \mathrm{PcO}_{2}$ and $\mathrm{pH}$ by appropriate electrodes. The minute volume and the $\mathrm{O}_{2}$ and $\mathrm{CO}_{2}$ concentrations of expired gas were also measured. Full technical details are given elsewhere (Stanley and Woodgate, 1971). These further procedures enabled us to calculate values in the supine position for the alveolar-arterial $\mathrm{O}_{2}$ difference breathing room air, the true shunt while breathing $99.5 \%$ oxygen, and the cardiac output by standard methods. The arterial-alveolar $\mathbf{N}_{2}$ difference, an index of pulmonary $\dot{V} / Q$ inequality, was measured in five cases by gas chromatography (Farhi et al., 1963).

\section{Results}

The physiological data are shown in Table II, where the patients are separated into two groups according to the presence or absence of arterial hypoxaemia. In the two most unsaturated patients (Cases 1 and 2), this hypoxaemia was largely due to true shunting. In the four remaining cases with hypoxaemia the levels of shunting werecomparatively minor and inadequate to be the sole explanationstif their increased values of alveolararterial $\mathrm{O}_{2}$ difference breathing air. Thus it seemed likely that other factors, such as pulmonary $\dot{\mathbf{V}} / \dot{Q}$ inequality, were also contributing to their hypoxaemia. This impression was supported by the additional finding that the arterial-alveolar $N_{2}$ difference was increased and the pulmonary transfer factor was reduced

TABLB I-Clinical Data of Patients with Hepatic Cirrhosis

\begin{tabular}{|c|c|c|c|c|c|c|c|c|c|c|}
\hline Case No. & Age & $\begin{array}{l}\text { Type of } \\
\text { Cirrhosis }\end{array}$ & $\begin{array}{c}\text { Encephal- } \\
\text { opathy }\end{array}$ & Ascites & Spiders & Clubbing & $\underset{(\mathbf{m g} / 100 \mathrm{ml})}{\text { Bilirubin }}$ & $\begin{array}{c}\text { Albumin } \\
\text { (g/100 ml) }\end{array}$ & $\begin{array}{c}\text { Globulin } \\
\text { (g/100 ml) }\end{array}$ & $\begin{array}{c}\text { Haemoglobin } \\
(\mathrm{g} / 100 \mathrm{ml})\end{array}$ \\
\hline $\begin{array}{r}1 \\
2 \\
3 \\
4 \\
5 \\
6 \\
7 \\
8 \\
9 \\
10 \\
11 \\
12\end{array}$ & $\begin{array}{l}30 \\
12 \\
30 \\
40 \\
60 \\
18 \\
59 \\
62 \\
43 \\
48 \\
52 \\
38\end{array}$ & $\begin{array}{l}\text { A.C.H. } \\
\text { A.C.H. } \\
\text { A.C.H. } \\
\text { Crypt. } \\
\text { Alc. } \\
\text { Fasc. } \\
\text { P.B.C. } \\
\text { P.B.C. } \\
\text { Crypt. } \\
\text { Alc. } \\
\text { Crypt. } \\
\text { Crypt. }\end{array}$ & $\begin{array}{l}\bar{z} \\
\overline{ \pm} \\
\bar{z} \\
\bar{z} \\
\bar{z} \\
=\end{array}$ & $\begin{array}{l}= \\
= \\
\bar{z} \\
\bar{z} \\
\bar{z} \\
= \\
=\end{array}$ & $\begin{array}{l}+ \\
+ \\
\pm \\
\pm \\
\pm \\
\pm \\
\pm \\
=\end{array}$ & $\begin{array}{l}+ \\
+ \\
+ \\
+ \\
+ \\
+ \\
\pm \\
\pm \\
= \\
=\end{array}$ & $\begin{array}{r}3.4 \\
2.0 \\
3.8 \\
2.6 \\
0.9 \\
7.5 \\
12.5 \\
5.6 \\
2.4 \\
1.5 \\
2.8 \\
0.8\end{array}$ & $\begin{array}{l}3.0 \\
2.4 \\
3.0 \\
3.2 \\
3.4 \\
2.0 \\
4.3 \\
3.5 \\
3.3 \\
3.7 \\
2.9 \\
3.4\end{array}$ & $\begin{array}{l}4 \cdot 3 \\
3 \cdot 8 \\
3 \cdot 8 \\
3 \cdot 1 \\
2.5 \\
7 \cdot 5 \\
3 \cdot 6 \\
3 \cdot 0 \\
4 \cdot 1 \\
3 \cdot 2 \\
4 \cdot 0 \\
3.8\end{array}$ & $\begin{array}{l}15.6 \\
17.0 \\
11.1 \\
13.6 \\
10.5 \\
10.8 \\
12.3 \\
12.4 \\
13.8 \\
13.6 \\
12.2 \\
14.8\end{array}$ \\
\hline
\end{tabular}

A.C.H. = Active chronic hepatitis. Crypt. = Cryptogenic cirrhosis. Alc. = Alcoholic cirrhosis. Fasc. $=$ Hepatic fascioliasis. P.B.C. $=$ Primary biliary cirrhosis. 
TABLE I-Cardiopulmonary Data in Cases of Liver Cirrhosis with and without Arterial Hypoxaemia

\begin{tabular}{|c|c|c|c|c|c|c|c|c|c|c|}
\hline Case No. & $\begin{array}{c}\text { Arterial O, } \\
\text { Tension } \\
\text { (mm Hg) }\end{array}$ & $\begin{array}{c}\text { Arterial CO, } \\
\text { Tension } \\
\text { (mm Hg) }\end{array}$ & $\begin{array}{c}\text { Alveolar- } \\
\text { arterial O, } \\
\text { difference } \\
\text { with Air } \\
\text { (mm Hg) }\end{array}$ & $\begin{array}{c}\text { True Shunt } \\
\text { with } \mathrm{O}_{2}(\% \\
\text { Cardiac } \\
\text { Output) }\end{array}$ & $\begin{array}{c}\text { Alveolar- } \\
\text { arterial N, } \\
\text { difference } \\
(\mathrm{mm} \mathrm{Hg})\end{array}$ & $\begin{array}{c}\text { CO Transfer } \\
\text { Factor (\% } \\
\text { Predicted) }\end{array}$ & $\begin{array}{c}\text { Cardiac } \\
\text { Index } \\
\left(1 . / \mathrm{min} / \mathrm{m}^{2}\right)\end{array}$ & $\begin{array}{c}\text { Mean } \\
\text { Pulmonary } \\
\text { Arterial } \\
\text { Pressure }\end{array}$ & $\begin{array}{c}\text { Pulmonary } \\
\text { Arterial } \\
\text { Wedge } \\
\text { Pressure } \\
\text { (mm Hg) }\end{array}$ & $\begin{array}{l}\text { Pulmonary } \\
\text { Vascular } \\
\text { Resistance } \\
\text { (Resist. } \\
\text { Units) }\end{array}$ \\
\hline $\begin{array}{l}1 \\
2 \\
3 \\
4 \\
5 \\
6\end{array}$ & $\begin{array}{l}43 \\
43 \\
65 \\
67 \\
72 \\
73\end{array}$ & $\begin{array}{l}27 \\
24 \\
33 \\
36 \\
32 \\
32\end{array}$ & $\begin{array}{l}82 \\
78 \\
49 \\
42 \\
44 \\
35\end{array}$ & $\begin{aligned} & \text { Wit } \\
& 35 \\
& 35 \\
& 12 \\
& 5 \\
& 5 \\
& 2\end{aligned}$ & $\begin{array}{c}\text { arterial hypos } \\
\overline{11} \\
19 \\
10 \\
17 \\
14\end{array}$ & \begin{tabular}{|l} 
emia \\
55 \\
57 \\
48 \\
32 \\
46 \\
46 \\
\end{tabular} & $\begin{array}{l}\overline{4 \cdot 4} \\
7 \cdot 0 \\
5 \cdot 2 \\
4 \cdot 9 \\
5 \cdot 4\end{array}$ & $\begin{array}{l}\overline{14} \\
34 \\
19 \\
16 \\
29\end{array}$ & $\begin{array}{r}\overline{0} \\
10 \\
9 \\
3\end{array}$ & $\begin{array}{l}\overline{3.2} \\
1.8 \\
0.9 \\
2.9\end{array}$ \\
\hline $\begin{array}{r}7 \\
8 \\
9 \\
10 \\
11 \\
12\end{array}$ & $\begin{array}{l}78 \\
83 \\
93 \\
86 \\
81 \\
87\end{array}$ & $\begin{array}{l}41 \\
37 \\
35 \\
37 \\
32 \\
37\end{array}$ & $\begin{array}{l}\text { Z2 } \\
\text { 三 }\end{array}$ & $\begin{array}{l}\frac{2}{z} \\
=\end{array}$ & $\begin{array}{l}= \\
=\end{array}$ & $\begin{array}{r}78 \\
88 \\
83 \\
95 \\
73 \\
105\end{array}$ & $\begin{array}{l}\frac{4 \cdot 2}{二} \\
=\end{array}$ & $\begin{array}{l}\frac{12}{二} \\
=\end{array}$ & $\begin{array}{l}= \\
\bar{z}\end{array}$ & $\begin{array}{l}= \\
\bar{Z}\end{array}$ \\
\hline Normal & $>77$ & $35-45$ & $<25$ & $<3$ & $<11$ & $>70$ & $3 \cdot 0-4.4$ & $8-22$ & $3-15$ & $<4$ \\
\hline
\end{tabular}
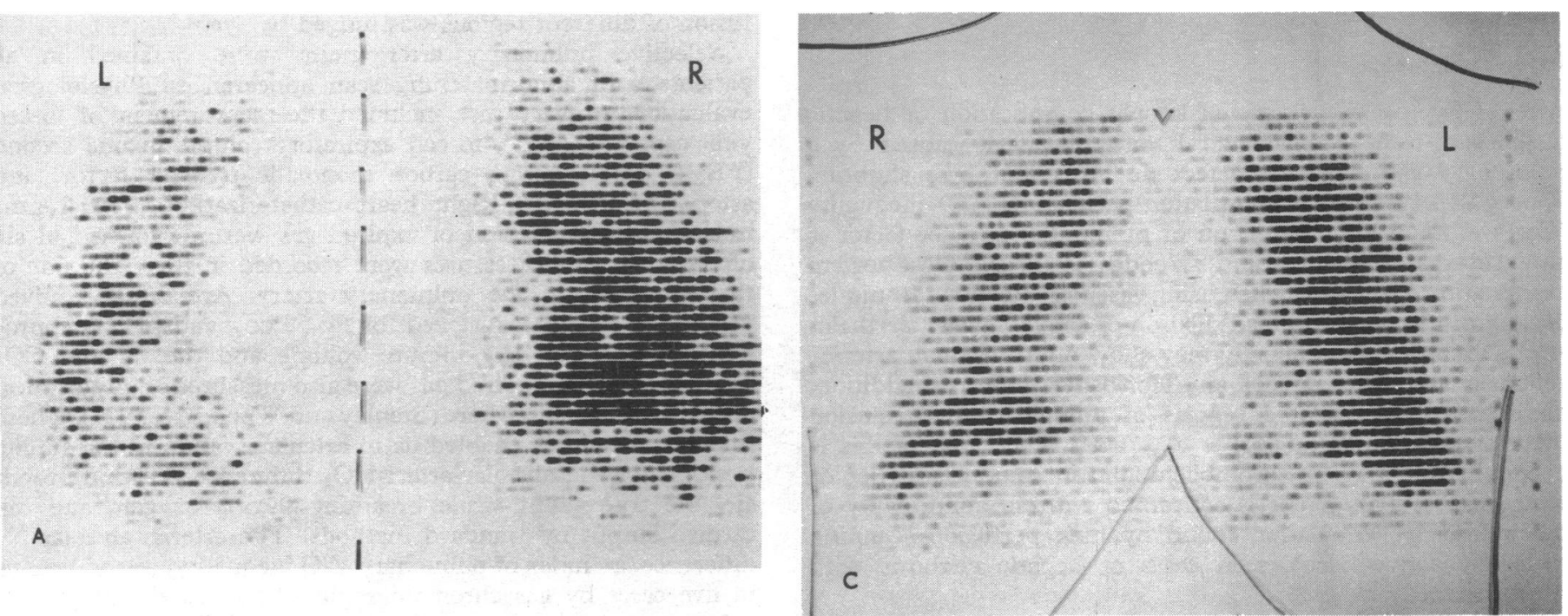

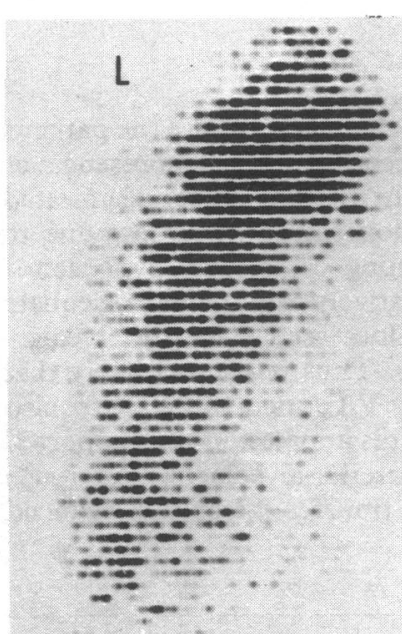

B

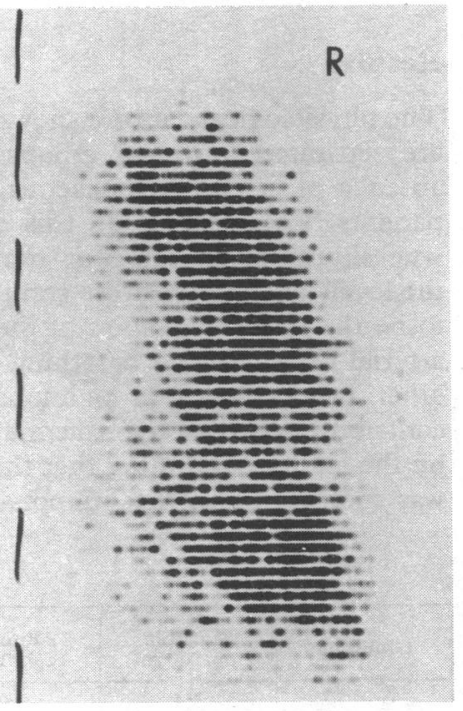

FIG. 1-Lung photoscans. A, Posterior scan in Case 3 using ${ }^{131}$ I-M.A.A. showing diminished particle uptake in left lung. B, Posterior scan in Case 4 using ${ }^{131}$ I-M.A.A. Radioactivity is unevenly distributed in middle and lower zones of both lungs and is reduced at left apex. C, Anterior scan in Case 6 using ${ }^{131} \mathrm{I}-\mathrm{M}$.A.A. showing reduced uptake of particles in left upper and middle lung zones. D, Anterior scan in Case 2 using $99 \mathrm{mTC}$ T.M.A.A. Distribution of radioactivity shows that few particles have lodged in lungs many have entered systemic circulation and have been taken up by spleen and liver.

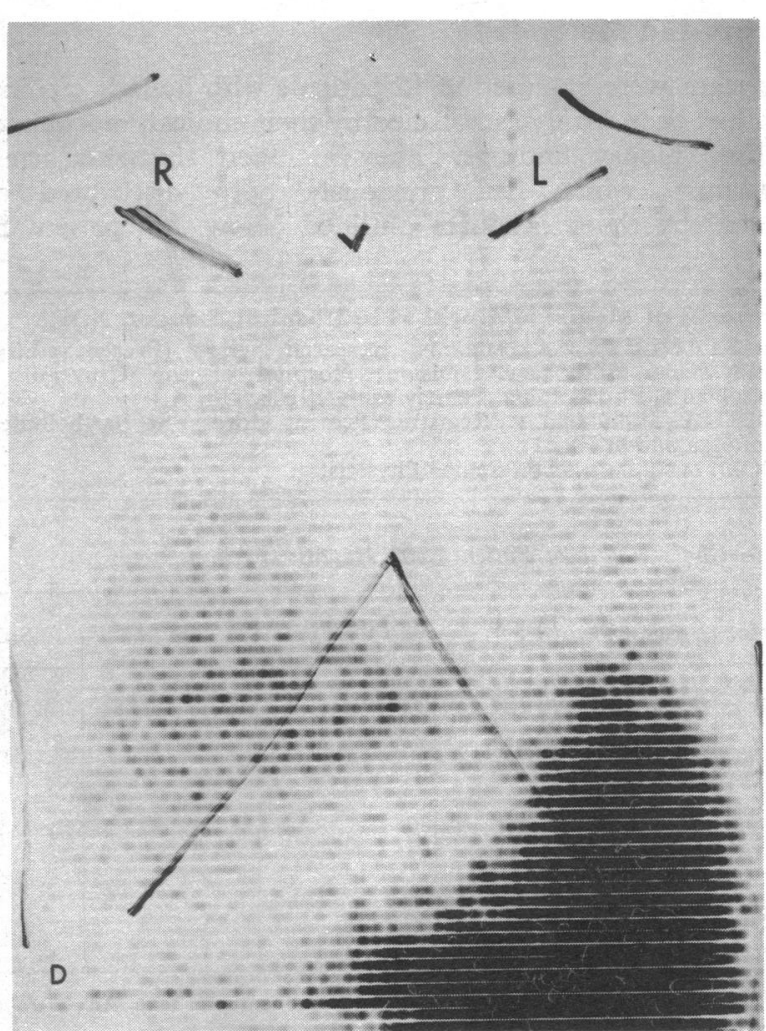



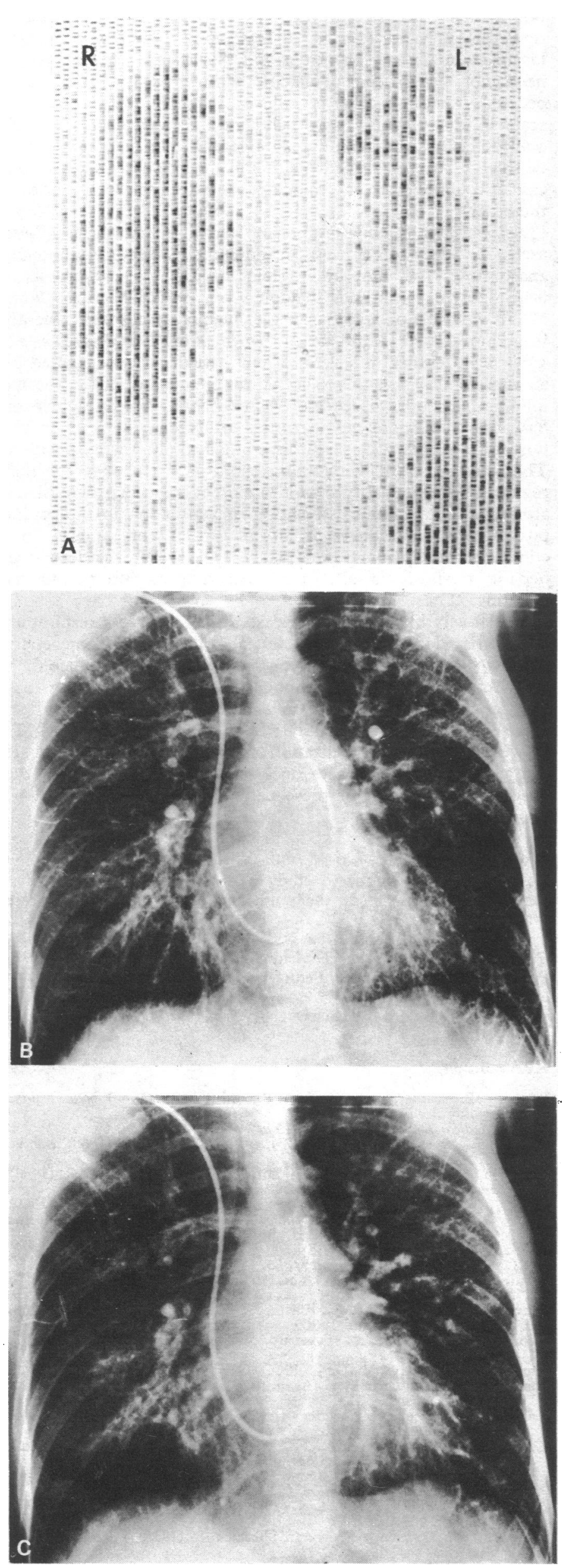

in most of these cases. Values of FEV 1 and FVC were normal in every case, which excluded any unsuspected obstructive or restrictive lung disease. In two patients (Cases 3 and 6) the pulmonary arterial pressure was increased, but both had high levels of cardiac output and their pulmonary vascular resistance was within normal limits. The chest radiographs in both these patients showed prominent hilar vascular shadows, but their electrocardiograms showed nothing abnormal.

Lung Scans.-Abnormal scans were seen in five out of the six cases with low arterial $\mathrm{O}_{2}$ tensions, whereas the scans were nor$\mathrm{mal}$ in all the patients without hypoxaemia. The scan defects are shown in Figs 1 and 2. In Case 2 the pulmonary image was very faint. Relative reduction of particle uptake by the entire left lung was present in Case 3 and by large parts of one lung in Cases 1 and 6. In Case 4 the radioactivity was virtually absent in the left apex and was distributed irregularly in the middle and lower zones of both lungs. A dense splenic shadow was present in the two cases with gross shunting (Cases 1 and 2), which indicated that numerous particles had not been trapped in the pulmonary vascular bed, presumably owing to direct arteriovenous anastomoses, and had thereby entered the systemic circulation. An interesting observation was also made in Case 1 . An initial scan showed only a very faint pulmonary image and the scintillation counts over the lungs gradually rose over a 20 -minute period, after which the final scan shown in Fig. 2 was made. The opening of arteriovenous communications is not limited to the pulmonary circulation in hepatic cirrhosis (Dal Palu et al., 1968) and this phenomenon may have represented recirculation of the particles owing to systemic as well as intrapulmonary arteriovenous anastomoses.

Pulmonary Arteriograms.-All major pulmonary arterial branches filled and no occlusions suggestive of emboli were seen. The capillary phase in Cases 1 and 2 showed a dense spongy appearance; this has previously been noted in cases of hepatic cirrhosis with cyanosis (Hansoti and Shah, 1966; El Gamal et al., 1970) and has been ascribed to multiple small arteriovenous anastomoses.

Comparison of Scans and Arteriograms.-An attempt was made to match the scan defects with regional variations of lung circulation seen on arteriography. In Case 6 the arteriogram appeared relatively avascular in the right upper lung zone, which was an area of diminished radioactivity in the perfusion scan. Such uneven distribution of blood flow to the pulmonary precapillaries may have contributed to the hypoxaemia of this subject, which was largely due to $\dot{V} / Q$ inequality. A different correlation of scan and arteriographic features was evident in Case 1 where the patient had a very large right to left shunt; her scan and arteriogram are shown in Fig. 2. In the arterial phase of her arteriogram there was preferential distribution of contrast medium to the left lower zone, which was the area with the most obviously abnormal small vessel pattern in the capillary phase; the first vein to opacify drained the left lower lobe. The overall appearances and the shorter arteriovenous transit time in the left lower lobe suggested an increased concentration of direct arteriovenous communications in this region of the lungs; the subsequent posterior perfusion scan showed reduced radioactivity in this region probably due to particles bypassing the capillary bed. In the remaining cases with regional scan defects no obvious correlations with arteriographic features were detectable. In Case 2 the lung scan showed a uniformly faint pulmonary image, the spongy small vessel pattern in the patient's arteriogram was present throughout the lungs, and all major tributaries of the pulmonary venous system opacified simultaneously.

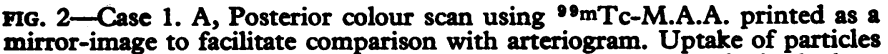
mirror-image to facilitate comparison with arteriogram. Uptake of particles B, Late arterial and capillary phase of pulmonary arteriogram shows a dense B, Late arterial and capillary phase of pulmonary arteriogram shows a dense
spongy small vessel pattern in left lower zone. $C$, Early venous phase of spongy small vessel pattern in left lower zone. C, Early venous phase of
pulmonary arteriogram shows that first vessel to opacify drains left lower pube. 


\section{Discussion}

Lung perfusion scanning with radioactive particles is most widely used in the diagnosis of large or medium-sized pulmonary emboli, but abnormal perfusion patterns may be shown by this technique in many other conditions including microembolism (Eaton et al., 1969), emphysema (LopezMajano et al., 1966), carcinoma of the bronchus (Garnett et al., 1968), asthma (Mishkin and Wagner, 1968), pneumonia (Lopez-Majano et al., 1965), congenital heart disease (Haroutunian et al., 1969), and heart failure (British Medical Fournal, 1969). In view of the several known disorders of the pulmonary circulation in hepatic cirrhosis it is not surprising that this disease may also give rise to abnormal lung scan appearances. Indeed, it is possible that scan defects in cirrhosis may have a varied pathogenesis.

The scan defects in the two most hypoxaemic cases were attributable at least in part to abnormal intrapulmonary arteriovenous communications in which the radioactive particles had failed to impact. Both patients had huge levels of right to left shunting and entry of particles into the systemic circulation was clearly shown by the high scintillation counts recorded over their spleens. Multiple arteriovenous anastomoses of up to $1 \mathrm{~mm}$ in diameter have been found post mortem in the lungs of a previously reported case of liver cirrhosis with severe cyanosis (Rydell and Hoffbauer, 1956), and the passage of intravenouslyinjected albumin macroaggregates into the systemic circulation has provided further evidence of abnormal pulmonary arteriovenous connexions in this disease. Moreover, the faintness of the pulmonary image in the scan in Case 2 indicated that very little of the patient's pulmonary blood flow could have passed through capillaries of normal diameter $(5-10 \mu \mathrm{m})$. The particle diameter $(10-15 \mu \mathrm{m})$ checked five minutes before injection was smaller than usual, but particles from the same batch had produced normal scan appearances in other patients studied the same day. Also, although her physiologically determined shunt was estimated to be $35 \%$ of the cardiac output, it remains possible that an even higher proportion of the pulmonary blood flow may have passed through vessels which might appear to be direct arteriovenous anastomoses rather than dilated capillaries on histological examination, since gas exchange probably occurs within arterioles in addition to the capillary network (Staub, 1961).

Scanning of extrathoracic organs had not been undertaken to evaluate the extent to which particles may have bypassed the pulmonary capillaries in the other three cases with scan defects. Their lower levels of shunting, however, and evidence of other disorders of gas exchange suggested that other factors might have caused their abnormal scan appearances. In this respect, Berthelot et al. (1966) found pronounced vasodilatation of precapillary pulmonary vessels without shunting in most cases of liver cirrhosis studied post mortem. Uneven distribution of this precapillary vasodilatation might be responsible for an uneven perfusion scan as blood flow would be enhanced in the most vasodilated areas. Alternatively, in the cases of patients with cirrhosis who develop pulmonary hypertension, regions of the lung with the greatest increases of vascular resistance could produce ischaemic areas on perfusion scanning. The cause of pulmonary hypertension in hepatic cirrhosis is uncertain; microembolism has been implicated in a few cases (Senior et al., 1968) but is rare, and was present in the necropsy material of only one out of 130 cases of cirrhosis whose lung histology was recently reviewed at this hospital (unpublished). Furthermore, the pulmonary vascular resistance was within normal limits in all the present cases, which argued against microembolism as a cause of their scan defects. High levels of cardiac output accounted for the increased pulmonary arterial pressures in Cases 3 and 6 . In Cases 2, 3, and 6 regional lung function in the vertical plane was also evaluated with radioactive xenon using averaged data from the right and left lungs. Details of these studies have been given in a separate report (Ruff et al., 1971). In brief, there was reduction of ventilation and blood flow at their lung bases in the seated position. It was speculated that this may have been due to early pulmonary oedema localized to the peribronchial and perivascular spaces, which need not have been detectable clinically. Such interstitial oedema provides another possible cause of the uneven perfusion scans in Cases 3 and 6, although it must be conceded that their scan defects in the supine position were of an unusual type to be solely the result of oedema, being strongly lateralized in one case and localized to the right upper and middle lung zones in the other.

Arterial hypoxaemia in hepatic cirrhosis has usually been ascribed to shunting through intrapulmonary or portapulmonary anastomoses, although the physiological importance of the latter is probably insignificant (Shaldon et al., 1961; Nakamura et al., 1965). The role of pulmonary $\dot{V} / \dot{Q}$ inequality has only recently been appreciated (Karetsky and Mithoeffer, 1967; Cotes et al., 1968. Its presence in several of our patients was confirmed by an increased arterial-alveolar $\mathrm{N}_{2}$ difference, which is specific for this particular disorder of gas exchange. The use of xenon has shown an increased vertical scatter of $\dot{V} / \dot{Q}$ ratios in the lungs of patients with cirrhosis studied in the seated position. The present work with radioactive particles suggests that regional $\dot{V} / Q$ inequality may also exist in the horizontal plane, although the regional distribution of ventilation in the supine position was not assessed in any of the present patients. In a clinical context, though, it is likely that severe unsaturation in hepatic cirrhosis is almost always due to intrapulmonary shunting. These patients tend to be young and have usually had relatively inactive liver disease for many years; respiratory symptoms dominate their clinical picture. No successful pharmacological method has yet been described to reduce their right to left shunt flow, although remission of shunting may occasionally accompany improvement of the underlying liver disease (Silverman et al., 1968; Stanley and Woodgate, 1972). However, the relative localization of intrapulmonary anastomoses in one of the present cases does raise the faint hope that the unsaturation of some of these patients could be alleviated by surgical means.

We wish to thank Professor Sheila Sherlock and Dr. Anthony Dawson for allowing us to study patients under their care. Dr. Simon Rees kindly made the pulmonary arteriogram of one case available to us.

Correspondence should be addressed to: Dr. N. N. Stanley, Cardiovascular-Pulmonary Division, Hospital for the University of Pennsylvania, Philadelphia, Pennsylvania 19104, U.S.A.

\section{References}

Berthelot, P., Walker, J. G., Sherlock, S., and Reid, L. (1966). New England Fournal of Medicine, 274, 291.

British Medical fournal, 1969, 4, 634

Cotes, J. E., Field, G. B., Brown, G. J. A., and Read, A. E. (1968). Lancet,

Dal Palu, C., Donnaggio, G., Dal Zotto, I., and Pessina, A. C. (1968). Scandinavian fournal of Gastroenterology, 3,425 .

Eaton, S. B., James, A. E., Majic, S. P., and Fleishner, F. G. (1969). American fournal of Roentgenology, Radium Therapy and Nuclear

El Gamal, M., Stoker, J. B., Spiers, E. M., and Whitaker, W. (1970). American fournal of Cardiology, 25, 490.

Farhi, L. E., Edwards, A. W. T., and Homma, T. (1963). Fournal of Applied Physiology, 18, 97.

Garnett, E. S., Goddard, B. A., Fraser, H. S., and MacLeod, W. M. (1968). British Medical fournal, 2, 209.

Georg, J., Mellemgaard, K., Tygstrup, N. and Winkler, K. (1960). Lancet, $1,852$.

Hansoti, M. D., and Shah, N. J. (1966). Circulation, 33, 71.

Haroutunian, L. M., Neill, C. A., and Wagner, H. N. (1969). American Fournal of Cardiology, 23, 387.

Karetsky, M. S., and Mithoeffer, J. C. (1967). American fournal of the Medical Sciences, 254, 797.

Lopez-Majano, V., Wagner, H. N., Tow, D. E., and Chernik, V. (1965). fournal of the American Medical Association, 194, 1053.

Lopez-Majano, V., Tow, D. E., and Wagner, H. N. (1966). Fournal of the American Medical Association, 197, 81

Mishkin, F. S., and Wagner, H. N. (1968). Fournal of the American Medical Association, 203, 1019.

Murrav, J. F., Dawson, A. M., and Sherlock, S. (1958). American fournal of Medicine, 24, 358. 
Nakamura, T., et al. (1965). Fournal of Laboratory and Clinical Medicine, 65,

Ruff, F., et al. (1971). Fournal of Clinical Investigation, 50, 2403.

Rydell, R., and Hoffbauer, F. W. (1956). American fournal of Medicine, 21, 450.

Segel, N., Kay, J. M., Bayley, T. J., and Paton, A. (1968). British Heart fournal, 30, 575 .
Senior, R. M., et al. (1968). Circulation, 37, 88.

Shaldon, S., et al. (1961). Nerv England fournal of Medicine, 265, 410

Silverman, A., Cooper, M. D., Moller, J. H., and Good, R. A. (1968) fournal of Pediatrics, 72, 70.

Thour, N. N

Stanley, N. N., and Woodgate, D. J. (1971). British Heart fournal, 33, 469. Stanley, N. N., and Woodgate, D. J. (1972). Thorax, 27, 372.

Staub, N. C. (1961). Angiology, 12, 469.

\title{
Isolated Pituitary Gonadotrophin Deficiency: Gonadotrophin Secretion after Synthetic Luteinizing Hormone and Follicle Stimulating Hormone-releasing Hormone
}

\author{
J. C. MARSHALL, \\ P. HARSOULIS, \\ D. C. ANDERSON, \\ A. S. MCNEILLY, \\ G. M. BESSER, \\ R. HALL
}

British Medical fournal, 1972, 4, 643-645

\section{Summary}

The responses of serum immunoreactive luteinizing hormone (LH) and follicle stimulating hormone (FSH) after intravenous injection of $100 \mu \mathrm{g}$ of synthetic LH/FSHRH have been studied in 14 patients with the syndrome of isolated pituitary gonadotrophin deficiency. Nine of the patients showed a rise of both hormones, two a small rise of FSH only, and three were unresponsive. In two of the unresponsive patients injection of a $500-\mu \mathrm{g}$ dose produced a small rise of LH only. Of the patients who responded, four had LH and FSH responses within the normal adult range, while in the others the responses were smaller and delayed. It is suggested that this syndrome is due to a lack of the hypothalamic-releasing hormone itself, rather than to a pituitary deficiency. However, repeat assessment after prolonged administration of the releasing hormone will be necessary before a pituitary disorder can be excluded in all patients. The synthetic LH/FSH-RH, preferably as a depot preparation, may provide a means of treating these patients to induce the development of puberty and subsequent fertility.

\section{Introduction}

With the availability of sensitive radioimmunoassays for luteinizing hormone ( $\mathrm{LH})$ and follicle stimulating hormone (FSH) the condition of isolated pituitary gonadotrophin deficiency (hypogonadotrophic hypogonadism) has been increasingly recognized as a cause of partial or complete failure of puberty. The condition may occur alone or be associated with other developmental abnormalities such as anosmia, harelip, cleft palate, and craniofacial asymmetry (Kallman et al., 1944). These patients have low or low-normal serum gonadotrophin levels which do not rise after clomiphene administration. Pituitary function is otherwise normal, though blunted growth hormone responses to hypoglycaemia have been described

Endocrine Unit, Department of Medicine, Royal Postgraduate Medical School, Hammersmith Hospital, London W12 0HS

J. C. MARSHALL, B.SC., M.R.C.P., M.R.C. Clinical Research Fellow P. HARSOULIS, M.D., Research Fellow

The Medical Professorial Unit and Department of Chemical Pathology, St. Bartholomew's Hospital, London EC1A 7BE

D. C. ANDERSON, M.SC., M.R.C.P., Lecturer in Medicine

A. S. MCNEILLY, B.SC., PH.D., Research Lecture

G. M. BESSER, M.D., M.R.C.P., Senior Lecturer in Edocrinology

Department of Medicine, Royal Victoria Infirmary, Newcastle upon Tyne

R. HALL, M.D., F.R.C.P., Professor of Medicine
(Odell et al., 1967; Hornichter et al., 1968; Bardin et al., 1969; Anderson et al., 1972).

It remains unclear whether the primary defect in this condition is at a hypothalamic or pituitary level, though the former site has been more often postulated, and histological abnormalities in the hypothalamus have been described (De Morsier and Gauthier, 1963). This view is supported also by the recent report of Naftolin et al., (1971) who found a small increase in serum LH in two patients after administration of a purified ovine hypothalamic extract.

The hypothalamic-releasing hormone for LH/FSH has recently been isolated and shown to be a decapeptide (Schally et al., 1971). The decapeptide has now been synthesized, and by using this material Besser et al. (1972) have shown that it releases $\mathrm{LH}$ and to a lesser extent FSH in normal men and women.

The aim of the present study was to establish whether patients with isolated gonadotrophin deficiency were able to secrete $\mathrm{LH}$ or FSH from the pituitary in response to an injection of $\mathrm{LH} /$ FSH-RH, and to assess the potential therapeutic value of the releasing hormone in such patients.

\section{Patients and Methods}

Fourteen patients (10 men and four women) were studied, and details of clinical features, previous therapy, and basal investigations are shown in the Table. The patients presented with complete or partial failure of puberty and the women with primary amenorrhoea. All had a eunuchoid habitus, a normal chromosome karyotype, and normal pituitary fossa radiographs. By using the criteria suggested by Hall et al. (1972), all the patients had normal pituitary function with respect to growth hormone and adrenocorticotrophic hormone (assessed by responses to insulin-induced hypoglycaemia) and thyroid stimulating hormone as judged by protein bound iodine and ${ }^{131}$ I uptake. Case 4, however, had an impaired growth hormone response, peak value $14 \mathrm{ng} / \mathrm{ml}$ (M.R.C. standard A HGH). Basal LH levels (mean of three to four estimations) were low in all patients and serum FSH was low in all but two (Cases 3 and 7). None of the subjects showed a rise of serum LH or FSH during a clomiphene test confirming the gonadotrophin deficiency, and all the men had low basal plasma $17 \beta$-hydroxyandrogen levels which rose during a human chorionic gonadotrophin stimulation test, indicating the presence of testicular Leydig cells (Anderson et al., 1972).

Assay Systems.-Serum LH and serum FSH were each measured in triplicate in two different radioimmunoassay systems, details of which have been given previously (Besser et al., 1972; Marshall et al., 1972). Results in the different assays for each hormone were essentially the same, and for clarity values from one system only are presented here (assay 2 , Besser et al., 1972). For comparison purposes the same standard preparation M.R.C. 69/104 (derived from LER 907) was used 